BMJ Open

Sport \&

Exercise

Medicine

\section{Psychometric evaluation of commonly used game-specific skills tests in rugby: A systematic review}

To cite: Oorschot S,

Chiwaridzo M,

CM Smits-Engelsman B.

Psychometric evaluation of commonly used gamespecific skills tests in rugby: A systematic review. BMJ Open Sport \& Exercise Medicine 2017;3:e000281. doi:10.1136/ bmjsem-2017-000281

- Additional material is published online only. To view please visit the journal online (http://dx.doi.org/10.1136/ bmjsem-2017-000281).

SO and MC contributed equally. Accepted 16 0ctober 2017

\section{(a) CrossMark}

${ }^{1}$ Faculty of Health, Medicine and Life Sciences, Department of Human Movement Sciences, Maastricht University, Maastricht, the Netherlands ${ }^{2}$ College of Health Sciences, Rehabilitation Department, University of Zimbabwe, Harare, Zimbabwe

${ }^{3}$ Faculty of Health Sciences, School of Health and Rehabilitation Sciences, Division of Physiotherapy, University of Cape Town, Cape Town, South Africa

Correspondence to

\section{ABSTRACT}

Objectives To (1) give an overview of commonly used game-specific skills tests in rugby and (2) evaluate available psychometric information of these tests. Methods The databases PubMed, MEDLINE CINAHL and Africa Wide information were systematically searched for articles published between January 1995 and March 2017. First, commonly used game-specific skills tests were identified. Second, the available psychometrics of these tests were evaluated and the methodological quality of the studies assessed using the Consensusbased Standards for the selection of health Measurement Instruments checklist. Studies included in the first step had to report detailed information on the construct and testing procedure of at least one game-specific skill, and studies included in the second step had additionally to report at least one psychometric property evaluating reliability, validity or responsiveness.

Results 287 articles were identified in the first step, of which 30 articles met the inclusion criteria and 64 articles were identified in the second step of which 10 articles were included. Reactive agility, tackling and simulated rugby games were the most commonly used tests. All 10 studies reporting psychometrics reported reliability outcomes, revealing mainly strong evidence. However, all studies scored poor or fair on methodological quality. Four studies reported validity outcomes in which mainly moderate evidence was indicated, but all articles had fair methodological quality.

Conclusion Game-specific skills tests indicated mainly high reliability and validity evidence, but the studies lacked methodological quality. Reactive agility seems to be a promising domain, but the specific tests need further development. Future high methodological quality studies are required in order to develop valid and reliable test batteries for rugby talent identification.

Trial registration number PROSPERO CRD42015029747.

\section{INTRODUCTION}

Rugby is a diverse collision sport played all over the world on amateur, semiprofessional and professional levels. ${ }^{1}$ Worldwide, it is played by $>7$ million players and the numbers are increasing. ${ }^{2}$ The $>2.47$ million tickets sold during the World Cup Rugby 2015 and the estimated 120 million people watching the final highlighted the popularity of the sport. ${ }^{3}$

\section{Key messages}

What is already known

- Rugby players are required to have a set of favourable anthropometric properties and welldeveloped physiological qualities, combined with a range of game-specific skills, both offensive and defensive, to cope with the demands of the game.

- Anthropometric and physiological characteristics, like body mass, maximal leg strength and lower body muscular power, have been shown to differentiate between different rugby playing levels.

- Game-specific skills tests in rugby seem to have predicting value in discriminating talented and less talented players, but a review investigating the underlying psychometrics of these tests is lacking.

\section{What are the new findings}

- Reactive agility, tackling skills and simulated rugby games are the most investigated game-specific skills.

- For game-specific skills, there is mainly moderate to strong evidence for reliability and validity, but the studies lack methodological quality.

- Reactive agility tests seem to be very promising, based on the preliminary evidence on validity, reliability and feasibility.

- Future research should be focused on detailed and standardised studies of game-specific skills tests. These studies should include detailed reports of the study procedures, critical evaluation of test design and adequate sample sizes of $n \geq 50$ or a sample size calculation.

- These findings can impact the current practice in the way that researchers, scouts and coaches will critically evaluate the tests they use to identify talented players, start focusing on new gamespecific skill domains and will come up with new tests in methodological rigorous studies to have an objective and psychometric sound backbone for their talent identification.

During the game, players participate in frequent bouts of intense activity, separated by short bouts of low-intensity activities. ${ }^{4}$ The high-intensity activities include sprinting, physical collisions and tackles and low-intensity activities include walking and jogging. ${ }^{4-6}$ During the course of a game, each team will 
perform on average 300 tackles, with semiprofessional rugby matches being played at a mean intensity of $81 \%$ $\mathrm{VO}^{2}$-max. ${ }^{78}$

To cope with these demands, rugby players are required to have a set of favourable anthropometric properties and well-developed physiological qualities, combined with a range of game-specific skills, both offensive and defensive. ${ }^{7-9}$ Identifying young players who are promising to develop these prerequisites of the game requires rugby clubs to have efficient talent identification programmes. ${ }^{1011}$ Fastened by the increase in popularity and professionalism in rugby, there is even more need to efficiently identify talent, so they come up with the most talented players and have the best teams in their category. Additionally, it is hard to predict the future potential of a player in the perspective of their development potential and factors surrounding the player. However, talent identification still remains mainly based on subjective assessments of scouts and coaches. To complement and increase the quality of this process, it would be beneficial to add a degree of objectivity by including sport science contributions on early talent predictors. ${ }^{11}{ }^{12}$ This can be done by including specific tests in the talent identification process, which should be chosen based on proven potential to predict talent in a methodological responsible way.

Several studies investigated factors that potentially predict talent. In these studies, variables such as body mass, maximal leg strength and lower body muscular power were shown to differentiate between first and second division rugby league players. ${ }^{8}{ }^{13}$ However, it remains questionable if the physiological qualities and anthropometric characteristics are the factors that discriminate between playing levels since higher levels of strength, power or body mass do not directly relate to better performance during the game. Not every amateur rugby player that increases levels of strength, power or body mass becomes an elite rugby player. The well-developed physical qualities must be translated into improved playing performance to have practical significance. ${ }^{9}$ Based on this, one presumes there should be additional, possibly even more important factors, which discriminate between talented and less talented players. In line with this, Gabbett et $\mathrm{al}^{14}$ found that skill-related characteristics discriminated most between successful and less successful rugby league players, while physiological or anthropometric characteristics did not. These findings suggest an important role for game-specific skills in rugby, and specific tests can potentially identify talented players who are able to translate the physical qualities to improved playing performance.

The inclusion of objective talent predicting assessments requires multidimensional test batteries on the unique set of anthropometric characteristics and physiological and game-specific skills qualities that are required. ${ }^{15}$ Different tests on talent predictors are available and used, but there are so far no overviews of the psychometric information underlying these tests and there is no gold standard yet. However, to be of added value in the process of talent identification, inclusion of tests should be based on objectivity, feasibility, validity and reliability. Additionally, a player should be measured at a young age and followed up for several years to investigate the progress of that specific variable in relation to the actual playing level, to judge if a certain variable has proven to be a talent predictor. However, studying talent predictors in this way requires longitudinal studies, which are generally expensive and time consuming and therefore often known groups validity approaches are used. In known groups validity approaches, groups that are known to differ or logically should differ are used and the test performance is compared over these groups. ${ }^{16}$

With this taken into account, the addition of sport science contributions could only be beneficial to the talent identification process when tests with good reliability and validity are being developed, so they can be used as an objective backbone for the subjective assessment of scouts and coaches. Therefore, it is required to have a clear overview of the available psychometric information of the commonly used tests in rugby. An overview of these tests can guide researchers, scouts and coaches in the process of development or inclusion of objective tests in talent identification programmes. In this review, we specifically focus on game-specific skills tests in rugby as these tests have not been investigated in detail, specifically not the underlying psychometrics. Besides the review about skills outcomes in different sports by Robertson et $a l,{ }^{15}$ there are, to our knowledge, no available reviews about psychometrics of game-specific skills tests in rugby. Therefore, the aim of this review was to systematically evaluate the level of evidence on psychometric properties of measures of game-specific skills, used for males in rugby. Information from this review will guide selection of measurement instruments for future studies and assist scouts and coaches in knowledge about common usage of game-specific skills in literature and their psychometric properties. The review is divided into two steps. First, the commonly used game-specific skills will be investigated to get an overview of the current situation in game-specific skills testing in rugby. Second, the available psychometrics of these tests and methodological quality of the studies will be analysed. The second step about the psychometrics will be the main focus of this review, while the first step will be used to put the psychometric information into perspective of what is commonly used in rugby.

\section{METHODS}

\section{Literature search}

A systematic review of all published literature was undertaken in accordance with the Preferred Reporting Items for Systematic Reviews and Meta-Analyses guidelines. ${ }^{17}$ A literature search for both steps was conducted on the databases PubMed, MEDLINE, CINAHL and Africa-Wide Information. Additionally, a hand search on the reference lists of included articles for the second step was done. The 
two steps varied in included articles because of an additional category in the search terms for the second step. The search terms for the first step included keywords of (1) game-specific skills, (2) age categories, (3) sports and (4) assessment tools. With these keywords game-specific skills tests could be found, without taking into account psychometric information. To find studies reporting psychometric information on these tests, an additional category of keywords was included in the second step. This was an extra category including keywords about (5) psychometric properties. The specific keywords of both categories can be found in the online supplementary appendix.

\section{Selection criteria}

English articles published between January 1995 and March 2017 were included. Only studies containing male subjects playing rugby league or rugby union were included. Opposed to the initial criteria set in the protocol on PROSPERO, we did to not include Australian Football players. The gameplay and required game-specific skills for these sports differ too much to make fair comparisons between these sports. No limitations were made for study design and age category. However, editorials, book chapters, poster and oral conference abstracts, unpublished theses, dissertations and case studies were excluded. Furthermore, studies published in non-English language and studies involving rugby participants living with disabilities were excluded.

Studies in the first step, about commonly used game-specific skills tests, had to report detailed information about the construct and testing procedure of at least one game-specific skill. Game-specific skills were defined as skills that directly relate to better performance during the game. These include, but are not limited to, ground skills, side-stepping, reactive agility, aerial and ground kick, passing for distance, passing for accuracy, kicking and catching (while moving) ${ }^{18}$ Studies included in the second step, about psychometric information, should have reported also on at least one psychometric property evaluating reliability, validity or responsiveness.

\section{Selection process}

Two reviewers (SO and $\mathrm{MC}$ ) independently screened titles, abstracts and, if necessary, full texts to assess inclusion or exclusion based on the predefined criteria. In case of disagreement, the reviewers discussed until consensus was reached. Otherwise disagreements were resolved through discussion or referral to a third reviewer (BSE). The full texts of titles and abstracts deemed potentially relevant were retrieved and reviewed for inclusion.

\section{Data synthesis}

The following data were extracted: publication details (first author, year of publication), title, purpose of the study, age of the participants, test groups, rugby code, game-specific skill construct evaluated, test(s) used to measure the construct, measurement properties assessed (reliability, validity and responsiveness), evidence level and Consensus-based Standards for the selection of health Measurement Instruments (COSMIN) rating.

For the reliability results, strong evidence was indicated with intraclass correlation coefficient (ICC) $\geq 0.70$, Pearson's correlation coefficient (PCC) $\geq 0.80$ or Cronbach's alpha $\geq 0.70$. For the validity results, the low effect size (ES) were indicated as weak evidence and high ES with strong evidence. Weak evidence was determined with ES 0.2-0.49, moderate evidence with ES 0.5-0.79 and strong evidence with $E S \geq 0.8$. Studies reporting validity results in $\omega^{2}$ were assessed based on criteria set in that specific study as no assessment of the $\omega^{2}$ is available in the COSMIN.

\section{Risk of bias assessment}

The methodological quality of the selected articles in the second step was assessed using the COSMIN checklist by two independent reviewers (SO and MC). ${ }^{19}$ This checklist was developed to rate the methodological quality of a study on one or more measurement properties. The rating is based on a point rating scale (poor, fair, good or excellent) on different items of design requirements and expected statistical methods. The overall rating for the methodological quality is indicated by the lowest score of these items.

\section{RESULTS}

\section{Search results}

In the initial procedure of the first step, 287 articles were retrieved. After removal of duplicates, screening the records and assessing full texts of potential studies, 30 articles were included in this step. The initial procedure in the second step delivered 64 articles. After removal of duplicates, screening the records and assessing full texts of potential studies, 10 articles were included. The flow diagram for search results and study selection is illustrated in figure 1.

\section{Step 1: commonly used tests}

An overview of the indicated game-specific skills and subjects used is shown in table 1 . Reactive agility and tackling skills were the most investigated skills, assessed both in seven articles. Three articles tested multiple skills. Articles assessed game-specific skills both in training setting and during match play. Two articles in training setting reported specifically on multiple skill-based tests, which were reactive passing and tackling under fatigue. ${ }^{20}{ }^{21}$ Of the 30 articles, 18 articles used rugby league players, 10 articles used rugby union players and 2 did not specify the rugby code.

\section{Step 2: psychometrics}

\section{Description of included studies}

The 10 included articles in the second step reported in total on 49 variables of psychometrics. Seven articles assessed rugby league players and three articles rugby union players. Four studies assessed reactive agility, whereby Gabbett $e t a t^{\hat{\theta}}$ also assessed other technical and 

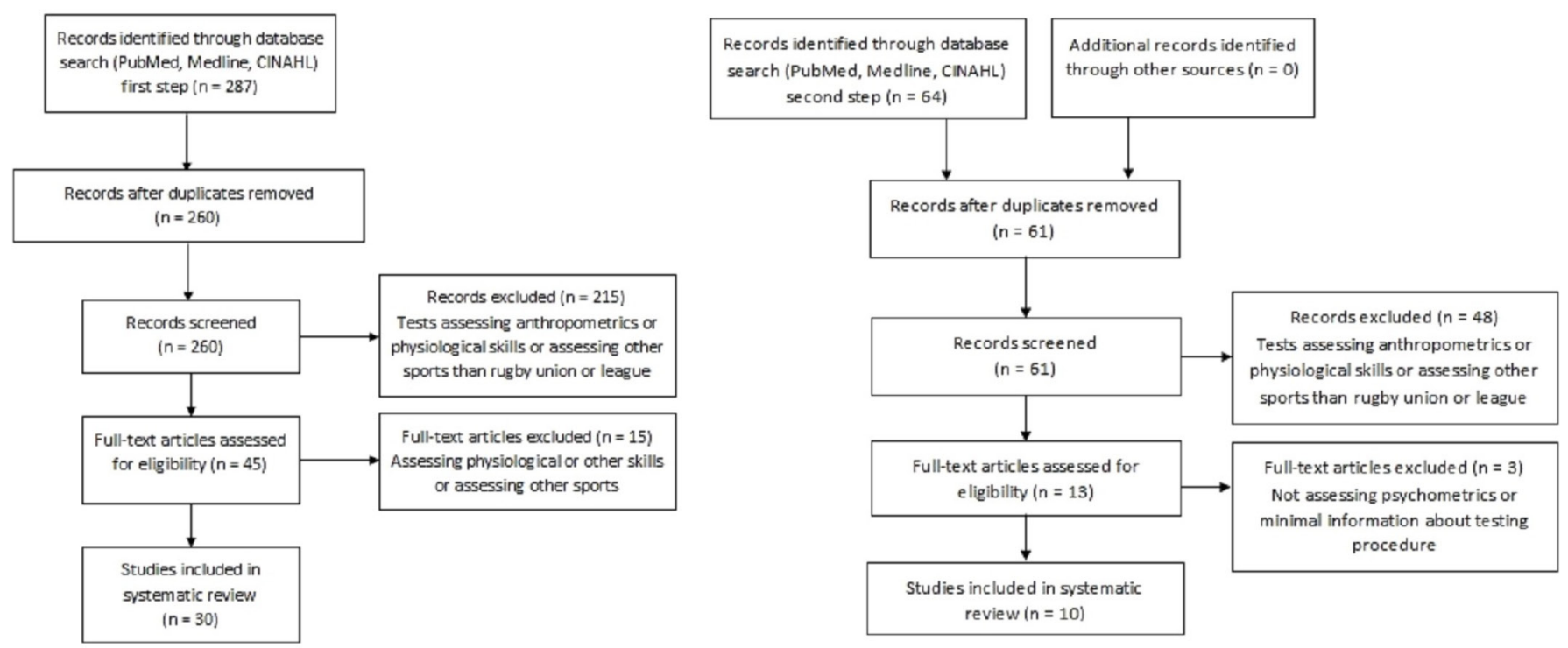

Figure 1 Flow diagram for search results and study selection.

perceptual skills. Also four studies assessed game-specific skills during a match. The other three studies focused on other technical or game-specific skills, like passing and tackling. Between articles reporting on the same skill, test designs differed in set-up, assessment and subjects used. Studies ranged from 9 to 218 subjects, with reported age ranging from $16.5 \pm 1.0$ to $25 \pm 4$ years. ${ }^{22} 23$ Subjects varied from first to second grade, elite senior to elite junior and experienced to non-experienced players.

\section{Reactive agility}

Gabbett et $a l^{24}$ and Gabbett et $a l^{9}$ used the same test design, with players required to follow direction of tester initiated movement to left or right through finish gate. Green $e t a l .^{25}$ used the design where players were required to sprint to $45^{\circ}$ change of direction point and change direction to left or right flashing finish gate. And Serpell et $a l^{26}$ used a completely different design and asked players to sprint towards a screen displaying action of sport-specific movement and change direction as playing defender.

\section{Game-specific skills during match}

The game-specific skills during match were all analysed after the match by an expert analyst and tested on interrater or intra-rater reliability. Gabbett et al. ${ }^{14}$ let two expert coaches assess playing skills (general, evasion, tackling/ defensive, offensive) on standardised criteria. Kempton et al, Sirotic et al and Bennett et al all coded specific events. ${ }^{232728}$ Kempton et $a l^{28}$ coded kicks received, passes, 'dummy-half' pass, ball caries and kicks (attacking and for territory). Sirotic et $a l^{27}$ assessed ball caries, support runs, touches of the ball, play-the-balls and tackles made. And Bennett $e t a l^{23}$ coded the ball caries, support runs, offensive misses, line breaks, line break assists and tackles completed or not completer.
Simulated rugby games and catching and passing

Furthermore, Stuart $e t a l^{22}$ assessed simulated rugby games, focused on different forms of sprinting, kicking and passing. Pienaar $e t a l^{10}$ analysed passing for distance, passing for accuracy over 4 and $7 \mathrm{~m}$ and catching while running.

An overview of all characteristics of the included studies is illustrated in table 2.

\section{Risk of bias assessment}

Reliability and validity outcomes were the only risk of bias assessment data that were described in detail in the included articles in the second step. No details on other risk of bias assessment variables were given. Therefore, only outcomes on these two factors of the risk of bias assessment were evaluated.

\section{Reliability outcomes}

All 10 articles included in the second step reported reliability outcomes. Five articles reported test-retest reliability, four articles intra-rater reliability and one article both interrater and intra-rater reliability. Also, 27 of the 33 reliability outcomes indicated strong evidence, with the highest ICCs for intra-rater reliability of 1.00 on line break assists and tackles completed during a match. ${ }^{23}$ Only Serpell et $a l^{26}$ indicated two ICCs of $\leq 0.5$ on perception and response time and confidence rating for test-retest reliability in a reactive agility test. The ICC was the most used analysis, PCC and Cronbach's alpha were both used once. Stuart et $a l^{29}$ reported coefficient of variation $(\mathrm{CoV})$, which indicated the level of dispersion around the mean. However, there is no COSMIN guideline for assessing CoV. In two studies, CoVs were $<10 \%$, and in two studies they found $\mathrm{CoVs}>10 \%$. Five of the articles were found to be of poor and five of fair methodological quality. The main reasons for this were missing information about percentage and handling of missing items, small sample size and methodological flaws. Methodological flaws included missing 
Table 1 Overview of game-specific skills found in studies included in the first step

\begin{tabular}{|c|c|c|}
\hline & Skill tested & Rugby code \\
\hline Green $^{25}$ & Reactive agility & Union \\
\hline Serpell $^{26}$ & Reactive agility & League \\
\hline Serpell $^{29}$ & Reactive agility & League \\
\hline Gabbett $^{24}$ & Reactive agility & League \\
\hline Gabbett $^{33}$ & Reactive agility & League \\
\hline Gabbett $^{9}$ & $\begin{array}{l}\text { Reactive agility, pattern } \\
\text { prediction/recognition, } \\
\text { tackling, catching, passing }\end{array}$ & League \\
\hline Gabbett $^{34}$ & $\begin{array}{l}\text { Reactive agility, pattern } \\
\text { prediction/recognition, } \\
\text { tackling, catching, passing }\end{array}$ & League \\
\hline Pavely ${ }^{20}$ & Reactive passing & Union \\
\hline Usman ${ }^{35}$ & Tackling & Union \\
\hline Gabbett $^{31}$ & Tackling & League \\
\hline Gabbett $^{21}$ & Tackling under fatigue & League \\
\hline Waldron ${ }^{36}$ & Tackling, catching and passing & League \\
\hline Lacome $^{37}$ & $\begin{array}{l}\text { Tackling and passing during } \\
\text { match }\end{array}$ & Union \\
\hline $\mathrm{Wu}^{38}$ & Scrummage & Not specified \\
\hline Pienaar $^{10}$ & Catching and passing & Union \\
\hline $\operatorname{Vaz}^{39}$ & Simulated rugby games & Union \\
\hline Higgings ${ }^{40}$ & Simulated rugby games & Union \\
\hline Stuart $^{22}$ & Simulated rugby games & Union \\
\hline Gabbett $^{41}$ & Simulated rugby games & League \\
\hline Sirotic $^{42}$ & $\begin{array}{l}\text { Game-specific skills per } \\
\text { minute during match }\end{array}$ & League \\
\hline Sirotic $^{27}$ & $\begin{array}{l}\text { Game-specific skills per } \\
\text { minute during match }\end{array}$ & League \\
\hline Kempton $^{28}$ & $\begin{array}{l}\text { Game-specific skills per } \\
\text { minute during match }\end{array}$ & League \\
\hline Bennett $^{23}$ & Skill involvement during match & League \\
\hline Lacome $^{43}$ & Skill involvement during match & Union \\
\hline Linthorne $e^{44}$ & Rugby kick & Not specified \\
\hline Cockcroft $^{45}$ & Rugby kick & Union \\
\hline Gabbett $^{46}$ & Two-on-one attacking drill & League \\
\hline Gabbett $^{47}$ & Two-on-one attacking drill & League \\
\hline Gabbett $^{14}$ & $\begin{array}{l}\text { Playing ability assessed by } \\
\text { coach }\end{array}$ & League \\
\hline Gabbett $^{48}$ & $\begin{array}{l}\text { Playing ability assessed by } \\
\text { coach }\end{array}$ & League \\
\hline
\end{tabular}

information on the participants, unclear study design and missing information on the retest situation in test-retest setting or about the second rater in inter-rater setting. The reliability outcomes are illustrated in table 3 .

Validity outcomes

Four articles reported construct validity outcomes based on known groups evaluations. Different groups were compared; from experienced to non-experienced and elite to elite youth. Three articles assessed reactive agility, reporting Cohen's d ES, and one article assessed passing, running, catching and kicking skills, reporting $\omega^{2}$. Practical significance was determined at $\omega^{2} \geq 14 \%$ on the basis of assessment by Pienaar et al. ${ }^{10}$ Four of the six ES on different variables of the reactive agility tests indicated moderate evidence and one ES indicated strong evidence. Highest was an ES of 1.14 found by Green $e t$ $a l^{25}$ on reactive agility speed compared between academy and club rugby union players. Lowest ES (0.34) indicated weak evidence, which was on response accuracy in a reactive agility test compared between first-grade and second-grade players, by Gabbett et al. ${ }^{24}$ The $\omega^{2}$ values varied from $10.6 \%$ for the passing for accuracy test on $4 \mathrm{~m}$ to $50.7 \%$ on the passing for accuracy test on $7 \mathrm{~m}$. Furthermore, all studies indicated fair methodological quality according to the COSMIN checklist. Main reasons were missing information on percentage and handling of missing items, low sample sizes and methodological flaws. Methodological flaws included missing information on the participants, unclear study design and missing information on how the validity results were determined.

\section{DISCUSSION}

The present systematic review investigated existing game-specific skills tests and evaluated available psychometrics of these tests. The main finding was that studies on these tests mainly indicated moderate to high evidence for reliability and validity. However, articles assessing psychometrics often lacked methodological quality (tables 3 and 4). Therefore, it still needs to be confirmed if the tests are really valid and reliable in more methodologically rigorous studies specifically designed to evaluate psychometric properties. Since the findings of the present review can be influenced by the procedures followed in the included studies (eg, incomplete description of the procedure, low sample sizes, data handling), the reported reliability and validity results should be interpreted with caution. The results of this systematic review can help researchers, scouts and coaches in the process of development or inclusion of objective game-specific skills tests in talent identifying programmes in rugby clubs.

\section{Game-specific skills}

In the first step of this systematic review, 30 articles reporting on game-specific skills were included. Reactive agility, tackling skills and simulated rugby games were the most studied skills. Reactive agility is defined as 'a rapid whole body movement with change of velocity or direction in response to a sports specific stimuli, ${ }^{29}$ Tackling and simulated rugby games were tested using multiple different set-ups, assessments and analyses. In the second step, 10 articles were included, in which reactive agility also was the most assessed skill. In these studies, mainly test-retest and intra-rater reliability were assessed. The majority of these studies indicated strong reliability evidence, meaning that the tests were relatively 
Table 2 Study characteristics and test design regarding studies included in the second step

\begin{tabular}{|c|c|c|c|c|c|}
\hline Author(s) & Rugby code & Skill tested & Subjects & $\begin{array}{l}\text { Age } \\
\text { (mean } \pm S D)\end{array}$ & Test design \\
\hline \multirow[t]{2}{*}{ Green $^{25}$} & Union & Reactive agility & Academy $(n=17)$ & $19 \pm 1.67$ & $\begin{array}{l}\text { Sprint to } 45^{\circ} \text { change of direction point and change } \\
\text { direction to left or right flashing finish gate }\end{array}$ \\
\hline & & & Club $(n=11)$ & $19 \pm 1.30$ & \\
\hline \multirow[t]{2}{*}{ Gabbett $^{24}$} & League & Reactive agility & First grade $(n=12)$ & $23.6 \pm 2.3$ & $\begin{array}{l}\text { Follow direction of tester (four scenarios) initiated } \\
\text { movement to left or right through finish gate }\end{array}$ \\
\hline & & & $\begin{array}{l}\text { Second grade } \\
(\mathrm{n}=30)\end{array}$ & & \\
\hline \multirow[t]{2}{*}{ Serpell ${ }^{26}$} & League & Reactive agility & Elite $(n=15)$ & Not reported & $\begin{array}{l}\text { Sprint towards screen displaying action of sport- } \\
\text { specific movement ( } 48 \text { scenarios) and change direction } \\
\text { as playing defender }\end{array}$ \\
\hline & & & Elite junior $(n=15)$ & & \\
\hline \multirow[t]{5}{*}{ Gabbett $^{9}$} & League & $\begin{array}{l}\text { Technical and } \\
\text { perceptual skills }\end{array}$ & First grade $(n=58)$ & $23.8 \pm 3.8$ & $\begin{array}{l}\text { Reactive agility: follow direction of tester (four } \\
\text { scenarios) initiated movement to left or right through } \\
\text { finish gate }\end{array}$ \\
\hline & & & & & $\begin{array}{l}\text { Pattern recall: recall player positions at time of video } \\
\text { footage occlusion }\end{array}$ \\
\hline & & & & & $\begin{array}{l}\text { Pattern prediction: predict next action at time of video } \\
\text { footage occlusion }\end{array}$ \\
\hline & & & & & $\begin{array}{l}\text { Tackling: } 1 \text {-on-1 tackling drill assessed on } \\
\text { standardised criteria by sport scientist }\end{array}$ \\
\hline & & & & & $\begin{array}{l}\text { Draw and pass: } 2-o n-1 \text { drill in single and dual-task } \\
\text { conditions assessed by sport scientist }\end{array}$ \\
\hline \multirow[t]{3}{*}{ Pienaar $^{10}$} & Union & Catching and passing & Experienced $(n=173)$ & Not reported & Passing for distance: passing as far as possible \\
\hline & & & $\begin{array}{l}\text { Non-experienced } \\
(\mathrm{n}=45)\end{array}$ & & $\begin{array}{l}\text { Passing for accuracy: passing over } 4 \text { and } 7 \mathrm{~m} \text { towards } \\
\text { target }\end{array}$ \\
\hline & & & & & Running and catching: catching the ball while running \\
\hline \multirow[t]{6}{*}{ Stuart $^{22}$} & Union & $\begin{array}{l}\text { Simulated rugby } \\
\text { games }\end{array}$ & Elite $(n=9)$ & $25 \pm 4$ & Kick for distance: kicking as far as possible \\
\hline & & & & & Kick-off for distance: kicking-off as far as possible \\
\hline & & & & & Offensive sprint: forward run with ball while swerving \\
\hline & & & & & $\begin{array}{l}\text { Defensive sprint: running forward and backward three } \\
\text { arcs }\end{array}$ \\
\hline & & & & & $\begin{array}{l}\text { Tackle sprint: tackle on tackle bag, running backward } \\
\text { with ball, making another tackle and run forward }\end{array}$ \\
\hline & & & & & $\begin{array}{l}\text { Passing accuracy: repeatedly pass ball as fast as } \\
\text { possible towards target }\end{array}$ \\
\hline Gabbett $^{14}$ & League & $\begin{array}{l}\text { Game-specific skills } \\
\text { during match }\end{array}$ & First grade $(n=86)$ & $22.5 \pm 4.9$ & $\begin{array}{l}\text { Two expert coaches assessing playing skills (general, } \\
\text { evasion, tackling/defensive, offensive) on standardised } \\
\text { criteria }\end{array}$ \\
\hline \multirow[t]{2}{*}{ Kempton $^{28}$} & League & $\begin{array}{l}\text { Game-specific skills } \\
\text { during match }\end{array}$ & Elite $(n=5)$ & Not reported & $\begin{array}{l}2 \times \text { first halves of } 10 \text { subjects coded on game-specific } \\
\text { skills analysed on standardised criteria by trained } \\
\text { operator from recordings of matches }\end{array}$ \\
\hline & & & Elite junior $(n=5)$ & & \\
\hline \multirow[t]{2}{*}{ Sirotic $^{27}$} & League & $\begin{array}{l}\text { Game-specific skills } \\
\text { during match }\end{array}$ & Elite (17) & $24.8 \pm 3.1$ & $\begin{array}{l}2 \times \text { first halves of nine matches analysed on game- } \\
\text { specific skills per minute of playing time }\end{array}$ \\
\hline & & & Semi-elite (22) & $22.1 \pm 2.4$ & \\
\hline Bennett $^{23}$ & League & $\begin{array}{l}\text { Game-specific skills } \\
\text { during match }\end{array}$ & Elite junior (45) & $16.5 \pm 1.0$ & $\begin{array}{l}2 \times \text { first halves of eight matches analysed on skill } \\
\text { involvement during match }\end{array}$ \\
\hline
\end{tabular}

consistent over different occasions or raters. Also, 4 of the 10 articles reported validity outcomes with ES, using known groups comparisons. In these studies, moderate to strong evidence was found for different reactive agility tests. None of the studies reported on comparison with some kind of gold standard, and for most game-specific skill domains there is no gold standard yet. With only four studies reporting validity there is a clear need for validity analyses of game-specific skills tests. Before tests can be of benefit in the talent identification process, 
Table 3 Reliability outcomes of studies included in the second step

\begin{tabular}{|c|c|c|c|c|c|c|c|c|}
\hline Author(s) & $\begin{array}{l}\text { Rugby } \\
\text { code }\end{array}$ & Skill tested & $\begin{array}{l}\text { Subjects } \\
\text { (N) }\end{array}$ & Reliability & Variable & Result & Evidence & COSMIN \\
\hline Green $^{25}$ & Union & $\begin{array}{l}\text { Reactive } \\
\text { agility }\end{array}$ & 11 & Test-retest & Reactive agility speed (s) & $\mathrm{ICC}=0.88, \mathrm{SEM}=0.09$ & + & Poor \\
\hline \multirow[t]{3}{*}{ Gabbett $^{24}$} & League & $\begin{array}{l}\text { Reactive } \\
\text { agility }\end{array}$ & 42 & Test-retest & Movement time (s) & $\mathrm{ICC}=0.92, \mathrm{TE}=2.1 \%$ & + & Fair \\
\hline & & & & & Decision time (ms) & $\mathrm{ICC}=0.95, \mathrm{TE}=7.8 \%$ & + & \\
\hline & & & & & Response accuracy & $\mathrm{ICC}=0.93, \mathrm{TE}=3.9 \%$ & + & \\
\hline \multirow[t]{3}{*}{ Serpell ${ }^{26}$} & League & $\begin{array}{l}\text { Reactive } \\
\text { agility }\end{array}$ & 15 & Test-retest & Total agility time (s) & $I C C=0.82, S E M=0.01$ & + & Fair \\
\hline & & & & & $\begin{array}{l}\text { Perception and response } \\
\text { time (s) }\end{array}$ & $\mathrm{ICC}=0.31, \mathrm{SEM}=0.01$ & - & \\
\hline & & & & & $\begin{array}{l}\text { Participants' confidence } \\
\text { about decision made (\%) }\end{array}$ & $I C C=0.50, S E M=2.12$ & - & \\
\hline \multirow[t]{7}{*}{ Gabbett $^{9}$} & League & $\begin{array}{l}\text { Technical and } \\
\text { perceptual } \\
\text { skills }\end{array}$ & 58 & Test-retest & Tackling assessment & $\mathrm{ICC}=0.83, \mathrm{TE}=3.3 \%$ & + & Poor \\
\hline & & & & & Draw and pass assessment & $\mathrm{ICC}=0.86, \mathrm{TE}=5.3 \%$ & + & \\
\hline & & & & & $\begin{array}{l}\text { Reactive agility, decision } \\
\text { accuracy }\end{array}$ & $\mathrm{ICC}=0.93, \mathrm{TE}=3.9 \%$ & + & \\
\hline & & & & & $\begin{array}{l}\text { Reactive agility, decision } \\
\text { time }\end{array}$ & $\mathrm{ICC}=0.95, \mathrm{TE}=7.8 \%$ & + & \\
\hline & & & & & Pattern recall & $\mathrm{ICC}=0.80, \mathrm{TE}=9.3 \%$ & + & \\
\hline & & & & & Pattern prediction & $\mathrm{ICC}=0.85, \mathrm{TE}=8.7 \%$ & + & \\
\hline & & & & Intra-rater & Playing performance & $\mathrm{ICC}>0.80, \mathrm{TE}<5.0 \%$ & + & \\
\hline \multirow[t]{4}{*}{ Pienaar $^{10}$} & $\begin{array}{l}\text { Not } \\
\text { specified }\end{array}$ & $\begin{array}{l}\text { Catching and } \\
\text { passing }\end{array}$ & 36 & Test-retest & Passing for distance & $\mathrm{PCC}=0.74$ & - & Fair \\
\hline & & & & & Passing for accuracy, $7 \mathrm{~m}$ & $\mathrm{PCC}=0.66$ & - & \\
\hline & & & & & Passing for accuracy, $4 \mathrm{~m}$ & $\mathrm{PCC}=0.39$ & - & \\
\hline & & & & & Running and catching & $\mathrm{PCC}=0.53$ & - & \\
\hline \multirow[t]{4}{*}{ Stuart ${ }^{22}$} & Union & $\begin{array}{l}\text { Simulated } \\
\text { rugby games }\end{array}$ & 9 & $\begin{array}{l}\text { Between- } \\
\text { subjects } \\
\text { CoV }\end{array}$ & Offensive sprint & $\mathrm{CoV}=13 \%$ & & Poor \\
\hline & & & & & Defensive sprint & $\mathrm{CoV}=9.2 \%$ & & \\
\hline & & & & & Tackle sprint & $\mathrm{CoV}=9.8 \%$ & & \\
\hline & & & & & Passing accuracy & $\mathrm{CoV}=20 \%$ & & \\
\hline \multirow[t]{2}{*}{ Gabbett $^{14}$} & League & $\begin{array}{l}\text { Game-specific } \\
\text { skills during } \\
\text { match }\end{array}$ & 86 & Intra-rater & & $\begin{array}{l}\mathrm{ICC}=0.85-0.98 \\
\mathrm{TE}=5.1 \%-5.3 \%\end{array}$ & + & Poor \\
\hline & & & & Inter-rater & & $\begin{array}{l}\mathrm{ICC}=0.84-0.94 \\
\mathrm{TE}=7.0 \%-9.0 \%\end{array}$ & + & \\
\hline Kempton $^{28}$ & League & $\begin{array}{l}\text { Game-specific } \\
\text { skills during } \\
\text { match }\end{array}$ & 10 & Intra-rater & Attempted tackle & $\alpha=0.81$ & + & Poor \\
\hline
\end{tabular}

Kick receive

Pass

'Dummy-half' pass

Ball carry

Kick (attacking)

Kick (territory)

ICC $=0.996, \quad+\quad$ Fair

skills during

TEM $=0.008$

match 
Table 3 Continued

\begin{tabular}{|c|c|c|c|c|c|c|c|c|}
\hline Author(s) & $\begin{array}{l}\text { Rugby } \\
\text { code }\end{array}$ & Skill tested & $\begin{array}{l}\text { Subjects } \\
\text { (N) }\end{array}$ & Reliability & Variable & Result & Evidence & COSMIN \\
\hline & & & & & Support runs & $\begin{array}{l}\text { ICC }=0.986 \\
\text { TEM }=0.010\end{array}$ & + & \\
\hline & & & & & Touches of the ball & $\begin{array}{l}\mathrm{ICC}=0.997 \\
\mathrm{TEM}=0.022\end{array}$ & + & \\
\hline & & & & & Play-the-balls & $\begin{array}{l}\mathrm{ICC}=0.997 \\
\mathrm{TEM}=0.008\end{array}$ & + & \\
\hline & & & & & Tackles made & $\begin{array}{l}\mathrm{ICC}=0.991 \\
\mathrm{TEM}=0.015\end{array}$ & + & \\
\hline \multirow[t]{7}{*}{ Bennett $^{23}$} & League & $\begin{array}{l}\text { Game-specific } \\
\text { skills during } \\
\text { match }\end{array}$ & 45 & Intra-rater & Ball carry & $\mathrm{ICC}=0.98, \mathrm{TEM}=0.053$ & + & Fair \\
\hline & & & & & Support run & $\mathrm{ICC}=0.86, \mathrm{TEM}=0.077$ & + & \\
\hline & & & & & Offensive miss & $\mathrm{ICC}=0.71, \mathrm{TEM}=0.061$ & + & \\
\hline & & & & & Line break & $\mathrm{ICC}=0.86, \mathrm{TEM}=0.007$ & + & \\
\hline & & & & & Line break assist & $I C C=1.00$, TEM $=0.000$ & + & \\
\hline & & & & & Tackle completed & $\mathrm{ICC}=1.00, \mathrm{TEM}=0.064$ & + & \\
\hline & & & & & Tackle not completed & $\mathrm{ICC}=0.99, \mathrm{TEM}=0.000$ & + & \\
\hline
\end{tabular}

'+', strong evidence; '-', limited evidence; $\alpha$, Cronbach's alpha; COSMIN, Consensus-based Standards for the selection of health Measurement Instruments; CoV, coefficient of variation; ICC, intraclass correlation coefficient; PCC Pearson's correlation coefficient, SEM, standard error of measurement; TE, typical error of measurement; TEM, technical error of measurement.

their predictive validity should be known, otherwise the implication of a specific score on these tests do not give meaningful insights with practical validity.

A strength of this systematic review was the use of the COSMIN checklist for the assessment of methodological quality of the articles. This assessment for articles reporting on reliability resulted in five articles indicated with poor and five articles with fair methodological quality. All articles reporting on validity scored fair on methodological quality, according to the COSMIN. These low scores were mainly caused by low sample sizes, methodological flaws that were not properly addressed

Table 4 Validity outcomes of studies included in the second step

\begin{tabular}{|c|c|c|c|c|c|c|c|c|}
\hline Author & Sport & Domain & Subjects (N) & Known groups & Variable & Result & Evidence & COSMIN \\
\hline Green $^{25}$ & $\begin{array}{l}\text { Rugby } \\
\text { union }\end{array}$ & $\begin{array}{l}\text { Reactive } \\
\text { agility }\end{array}$ & 28 & $\begin{array}{l}\text { Academy vs } \\
\text { club }\end{array}$ & Reactive agility speed (s) & $E S=1.14$ & ++ & Fair \\
\hline \multirow[t]{3}{*}{ Gabbett $^{24}$} & $\begin{array}{l}\text { Rugby } \\
\text { league }\end{array}$ & $\begin{array}{l}\text { Reactive } \\
\text { agility }\end{array}$ & 42 & $\begin{array}{l}\text { First grade vs } \\
\text { second grade }\end{array}$ & Movement time (s) & $\mathrm{ES}=0.73$ & + & Fair \\
\hline & & & & & Decision time (ms) & $E S=0.54$ & + & \\
\hline & & & & & Response accuracy & $E S=0.34$ & - & \\
\hline \multirow[t]{2}{*}{ Serpell ${ }^{26}$} & $\begin{array}{l}\text { Rugby } \\
\text { league }\end{array}$ & $\begin{array}{l}\text { Reactive } \\
\text { agility }\end{array}$ & 30 & $\begin{array}{l}\text { Elite players } \\
\text { vs elite youth } \\
\text { players }\end{array}$ & Total agility time (s) & $E S=0.56$ & + & Fair \\
\hline & & & & & $\begin{array}{l}\text { Perception and response } \\
\text { time }(\mathrm{s})\end{array}$ & $\mathrm{ES}=0.68$ & + & \\
\hline \multirow[t]{6}{*}{ Pienaar $^{10}$} & Rugby & $\begin{array}{l}\text { Rugby } \\
\text { skills }\end{array}$ & 218 & $\begin{array}{l}\text { Experienced vs } \\
\text { non-experienced }\end{array}$ & Passing for distance $(\mathrm{m})$ & $\omega^{2}=32.4$ & + & Fair \\
\hline & & & & & Passing for accuracy, $7 \mathrm{~m}$ & $\omega^{2}=50.7$ & + & \\
\hline & & & & & Passing for accuracy, $4 \mathrm{~m}$ & $\omega^{2}=10.6$ & - & \\
\hline & & & & & Running and catching & $\omega^{2}=23.3$ & + & \\
\hline & & & & & Kick for distance $(\mathrm{m})$ & $\omega^{2}=29.4$ & + & \\
\hline & & & & & Kick-off for distance $(\mathrm{m})$ & $\omega^{2}=13.9$ & - & \\
\hline
\end{tabular}

'++', strong evidence; '+', moderate evidence; '-', weak evidence; COSMIN, Consensus-based Standards for the selection of health Measurement Instruments; ES, effect size. 
and lack of information about percentage and handling of missing items. The low methodological quality could be the result of the finding that most studies were not specifically designed to assess psychometrics. The studies primarily focused on relations between test outcomes and playing groups. Assessing psychometrics seemed to be a side issue, causing minimal details on testing procedures. Therefore, we recommend researchers to come up with detailed and standardised studies of game-specific skills tests in rugby. These studies should include detailed reports of the study procedures, critical evaluation of test design and adequate sample sizes of $n \geq 50$, according to the COSMIN guidelines, or a sample size calculation. These recommendations are challenging to apply in the real world, but are necessary to come up with studies with high methodological quality and be able to work towards a better underlayment of the game-specific skills tests.

\section{Psychometrics}

The included articles varied in test design, subjects and statistical analyses used. Therefore, comparison of psychometrics over different studies was difficult. For example, three different protocols were used in four reactive agility tests. These studies used different cues to react on, like flashing timing gates, directions of a tester or a screen displaying sport-specific actions. Arguably, different outcomes are found when different test designs or groups are compared. Therefore, standardisation and detailed reporting is required. Furthermore, objective guidelines for interpretation of outcomes should be developed, taking into account the specific age and playing position groups. These guidelines have to be based on game requirements for the playing groups, which can be followed by developing levels of minimal requirements for the different groups. For determining these guidelines, promising techniques like Global Positioning System tracking and video analyses can be used.

Some interesting findings of the studies included in the second step were that the passing tests of Pienaar $e t a l^{10}$ and Stuart $e t a t^{22}$ seemed to have difficulties to establish good reproducibility, based on the low PCCs of 0.39 and 0.74 of Pienaar et al and the high $\mathrm{CoV}$ of $20 \%$ for passing accuracy in the study of Stuart $e t a l^{1022}$ Also differences were found between studies using reactive agility tests. Serpell $e t a t^{26}$ indicated weak correlations between test and retest measurement in elite youth rugby league players for perception and response time and confidence rating (ICC $=0.31$ and 0.50 , respectively). Although, a strong correlation $(\mathrm{ICC}=0.82)$ on the test and retest measurement for total reactive agility time was found. This could be the result of players reacting differently on the cues in the test and retest, while keeping their total reactive agility time relatively constant. However, Gabbett et al contradict this finding because they found strong correlations between the test and retest of their reactive agility test for both decision time and response accuracy, with ICCs of 0.95 and 0.93 , respectively. ${ }^{24}$ Furthermore, Pienaar $e t a l^{10}$ found large differences between the performance of experienced and non-experienced players on passing for accuracy over 4 and $7 \mathrm{~m}$, respectively, $\omega^{2}$ of $10.6 \%$ and $50.7 \% .^{10}$ The difference in the passing test was only $3 \mathrm{~m}$, but the passing test over $7 \mathrm{~m}$ had the ability to better discriminate between experienced and non-experienced players than the passing test over $4 \mathrm{~m}$. However, it remains unclear if this difference in discriminant power between the 4 and $7 \mathrm{~m}$ passing test of Pienaar $e t a l^{10}$ resulted from different test design, subject selection, technique or other reasons.

Comparison of the reliability and validity outcomes resulted in some relatively low reliability and high validity outcomes found on the same test. This happened mainly on reactive agility and passing tests. For example, Pienaar et $a l^{10}$ found in their passing for accuracy test over $7 \mathrm{~m} \mathrm{a}$ relatively low PCC of 0.66 for the test-retest situation, but a relatively high $\omega^{2}$ of $50.7 \%$ for the discriminative validity between experienced and non-experienced players. This indicated the ability to discriminate between different groups, but groups showed inconsistent patterns over different test occasions. Therefore, stricter procedures could be developed to decrease variability. Moreover, it would be of interest to gain information about decisions made by the same player in the same situation or about decisions made by different players in a similar situation. This 'inter-player' and 'intra-player' reliability could be important, especially in reactive agility tests to evaluate decision-making patterns of specific players. Possibly this decision-making ability differs between playing levels and can partly explain the difference between talented and less talented players.

\section{Reactive agility}

Of all the different game-specific skills that were assessed, reactive agility seems to be the most promising skill to discriminate between different playing groups. Outcomes of studies analysing reactive agility revealed that higher-skilled players have faster decision-making and change of direction compared with lower-skilled players. Serpell et $a l^{26}$ argued that high-performance players are able to identify key sport-specific kinematic cues earlier than low-performance players and therefore can react quicker. These predictive features in highly skilled players make it more difficult to tackle them in attacking play or make it easier for them to adapt to opponent movements in defensive play. Besides the requirement of high methodological quality studies on this skill, all forms of validity and reliability, and the underlying principle of the skill should be further investigated. With critical evaluation and expert consensus, a gold standard for reactive agility can be developed, which can be used as reference test for new developments in this game-specific skill. Ecological validity should be taken into account in these tests, with Serpell et $a l^{20}$ being promising by using videos of real-time game situations as cues to react on. The lack of ecological valid tests is also highlighted by the fact that no studies assessed validity in match play situations. These factors should be considered when new tests are developed or existing tests are adapted. 


\section{Limitations}

Like all systematic reviews, the quality of this review is dependent on articles identified and included. MeSH terms were not used for all possible search terms in the search strategy of this review, which could have led to missed information. On this specific topic there were limited data available, which made it hard to draw strong conclusions. It can be argued that studies on sports comparable to rugby, like American and Australian football, should have been included, but inclusion of these sports would have implied unfair comparisons, based on significant differences in rules and gameplay. Furthermore, it should be considered that most articles assessed rugby league players. This can partly be explained by the relatively high amount of studies of Gabbett et al, which studied rugby league only. Possibly, this could have biased the results towards tests more focused on rugby league, without taking into account the minor differences between both rugby codes, like the contest after a tackle, points scored with specific actions and the 'six tackle rule'. Another limitation is the inclusion of articles with athletes from all age ranges as this could have led to unfair comparisons. This was due to the limited articles available and the focus of this review to analyse all the literature available on this topic. Readers or coaches should note that when using information about psychometric data from game-specific tests in this review it needs to be established whether the participants involved in such reported studies share similar characteristics to the populations the results are applied to. As a last point, it should be considered for future studies if the COSMIN rating as being used in this review is the best way to assess the methodological quality of the studies. Potentially other, more correct analyses or definitions are available.

\section{Future directions}

For future studies, we recommend researchers to differentiate between playing positions (groups) and to study game-specific skills in situations that mimic actual game situations. Now most skills are assessed in isolated and standardised settings. However, based on the gameplay of rugby it is suggested that additional skills are important, for example, skill performance while being fatigued. Logically, the closed skill of, for example, passing is useful, but potentially passing skills while fatigued is even more important. As fatigue has shown to influence tackling ability, with fatigue resulting in progressive reductions in tackling technique, this could also be the case for passing skills. ${ }^{2130}$ During most game phases, and especially the end of the second half, there is a level of fatigue among the rugby player passing the ball. A suggestion for testing these skills with and without the influence of fatigue could be to perform a passing test, both before and after a maximal endurance test. Furthermore, an additional skill that seems to be important is the ability to 'read the game'. A player that reads the game well is better in avoiding situations with risk on being tackled, can better create attacking opportunities and can reduce situations of making passing or kicking mistakes. Moreover, a player can have an excellent reactive agility score in an isolated testing situation, but if the player makes wrong decisions during the game about where to run and constantly runs into 'traffic', the player has no benefit of his excellent reactive agility score. Potentially, a player with a lower reactive agility score, but with better ability to read the game, is more successful during a game. This is in line with the findings from Gabbett $e t a l^{31}$, which found that rugby league players with poor reactive agility scores had a lower risk of injury. They suggested that these players might inadvertently avoid the heavy collisions that result in injury, or at best result in partial contact that does not result in exposure to the full force of a tackle, because of their low reactive agility. It can be that this was also due to the better ability to read the game, which makes this an interesting variable to assess in further studies.

With these findings taken into consideration, we recommend a change of direction in game-specific skills testing in rugby before tests are further developed. Because there are no high methodological quality studies, which analyse validity and reliability, there is a need for more methodologically rigorous studies, specifically designed to evaluate psychometric properties of game-specific skills tests. Otherwise it is unclear to what extent the findings of studies assessing game-specific skills are influenced by the test procedures followed. Because of the limited studies on validity found, there should be more studies focusing on the validity of these tests to be able to place the results in the context of predictive value for talent identification. Furthermore, it should be analysed if the currently used game-specific skills tests are clear reflections of the requirements of the game. Potentially a new view on testing and new categories of testing should be developed. Only after addressing these features in game-specific skills testing we recommend to go on with analysing game-specific skills in the way it is currently done. After this consideration, game-specific skills tests can be included as objective tests to complement talent-identifying programmes in rugby clubs.

\section{CONCLUSION}

Articles assessing psychometrics of game-specific skills tests mainly indicated moderate to high evidence on reliability and validity measures, but the studies lacked methodological quality. Future research should focus on high methodological quality studies to indicate valid and reliable game-specific skills tests in rugby, preferably focused on specific playing positions. Reactive agility is the most studied and promising skill, and should be further investigated to find the best testing procedure and create a gold standard. This systematic review can help researchers, scouts and coaches in the process of development or inclusion of objective game-specific skills tests in talent identifying programmes in rugby clubs, which can function as an objective backbone for talent identification by scouts and coaches.

\section{Competing interests None declared.}

Provenance and peer review Not commissioned; externally peer reviewed. 
Open Access This is an Open Access article distributed in accordance with the Creative Commons Attribution Non Commercial (CC BY-NC 4.0) license, which permits others to distribute, remix, adapt, build upon this work non-commercially, and license their derivative works on different terms, provided the original work is properly cited and the use is non-commercial. See: http://creativecommons.org/ licenses/by-nc/4.0/

C) Article author(s) (or their employer(s) unless otherwise stated in the text of the article) 2017. All rights reserved. No commercial use is permitted unless otherwise expressly granted.

\section{REFERENCES}

1. Gabbett TJ, Seibold AJ. Relationship between tests of physical qualities, team selection, and physical match performance in semiprofessional rugby league players. J Strength Cond Res 2013;27:3259-65.

2. Rugby W. Mapping the global popularity of rugby. 2014 http:// pulse-static-files.s3.amazonaws.com/worldrugby/photo/2015/03/ 05/61b7a966-a65a-4952-8b71-74bed89a8d7c/WR_2014_Player_ Numbers.jpg

3. Rugby W. RWC 2015 declared biggest and besttournament to date. 2015 http://www.rugbyworldcup.com/news/121819

4. Gabbett TJ. Physiological characteristics of junior and senior rugby league players. Br J Sports Med 2002;36:334-9.

5. Gibbs N. Injuries in professional rugby league. A three-year prospective study of the South Sydney Professional Rugby League Football Club. Am J Sports Med 1993;21:696-700.

6. Stephenson S, Gissane C, Jennings D. Injury in rugby league: a four year prospective survey. Br J Sports Med 1996;30:331-4.

7. Gabbett TJ. Science of rugby league football: a review. J Sports Sci 2005;23:961-76.

8. Gabbett TJ, Jenkins DG, Abernethy B. Correlates of tackling ability in high-performance rugby league players. J Strength Cond Res 2011;25:72-9.

9. Gabbett TJ, Jenkins DG, Abernethy B. Relationships between physiological, anthropometric, and skill qualities and playing performance in professional rugby league players. J Sports Sci 2011;29:1655-64.

10. Pienaar AE, Spamer MJ, Steyn HS. Identifying and developing rugby talent among 10-year-old boys: a practical model. J Sports Sci 1998;16:691-9.

11. Williams AM, Reilly T. Talent identification and development in soccer. J Sports Sci 2000;18:657-67.

12. Howe MJ, Davidson JW, Sloboda JA. Innate talents: reality or myth? Behav Brain Sci 1998;21:399-407.

13. Baker DG, Newton RU. Comparison of lower body strength, power, acceleration, speed, agility, and sprint momentum to describe and compare playing rank among professional rugby league players. $J$ Strength Cond Res 2008;22:153-8.

14. Gabbett T, Kelly J, Pezet T. Relationship between physical fitness and playing ability in rugby league players. J Strength Cond Res 2007;21:1126-33.

15. Robertson SJ, Burnett AF, Cochrane J. Tests examining skill outcomes in sport: a systematic review of measurement properties and feasibility. Sports Med 2014;44:501-18.

16. Davidson M, Validity K-G. Michalos AC, ed. Encyclopedia of quality of life and well-being research. Dordrecht: Springer Netherlands, 2014:3481-2.

17. Moher D, Liberati A, Tetzlaff J, et al. Preferred reporting items for systematic reviews and meta-analyses: the PRISMA statement. $J$ Clin Epidemiol 2009;62:1006-12.

18. Gent M, Spamer E. Comparisons of positional groups in terms of anthropometric, rugby-specific skills, physical and motor components among u13, u16, u18 and u19 elite rugby players. Kinesiology 2005;37:50-63.

19. Mokkink LB, Terwee CB, Knol DL, et al. Protocol of the COSMIN study: consensus-based standards for the selection of health measurement instruments. BMC Med Res Methodol 2006;6:2.

20. Pavely S, Adams RD, Di Francesco T, et al. Execution and outcome differences between passes to the left and right made by first-grade rugby union players. Phys Ther Sport 2009;10:136-41.

21. Gabbett TJ. Influence of fatigue on tackling ability in rugby league players: role of muscular strength, endurance, and aerobic qualities. PLoS One 2016;11:e0163161.

22. Stuart GR, Hopkins WG, Cook C, et al. Multiple effects of caffeine on simulated high-intensity team-sport performance. Med Sci Sports Exerc 2005;37:1998-2005.
23. Bennett KJ, Fransen J, Scott BR, et al. Positional group significantly influences the offensive and defensive skill involvements of junior representative rugby league players during match play. J Sports Sci 2016;34:1542-6.

24. Gabbett TJ, Kelly JN, Sheppard JM. Speed, change of direction speed, and reactive agility of rugby league players. J Strength Cond Res 2008;22:174-81.

25. Green BS, Blake C, Caulfield BM. A valid field test protocol of linear speed and agility in rugby union. J Strength Cond Res 2011;25:1256-62.

26. Serpell BG, Ford M, Young WB. The development of a new test of agility for rugby league. J Strength Cond Res 2010;24:3270-7

27. Sirotic AC, Coutts AJ, Knowles $\mathrm{H}$, et al. A comparison of match demands between elite and semi-elite rugby league competition. J Sports Sci 2009;27:203-11.

28. Kempton T, Sirotic AC, Cameron M, et al. Match-related fatigue reduces physical and technical performance during elite rugby league match-play: a case study. J Sports Sci 2013;31:1770-80.

29. Serpell BG, Young WB, Ford M. Are the perceptual and decisionmaking components of agility trainable? A preliminary investigation J Strength Cond Res 2011;25:1240-8.

30. Sheppard JM, Young WB. Agility literature review: classifications, training and testing. J Sports Sci 2006;24:919-32

31. Gabbett TJ. Influence of fatigue on tackling technique in rugby league players. J Strength Cond Res 2008;22:625-32.

32. Gabbett TJ, Ullah S, Jenkins D, et al. Skill qualities as risk factors for contact injury in professional rugby league players. J Sports Sci 2012;30:1421-7.

33. Gabbett T, Benton D. Reactive agility of rugby league players. J Sci Med Sport 2009;12:212-4.

34. Gabbett TJ, Jenkins DG, Abernethy B. Relative importance of physiological, anthropometric, and skill qualities to team selection in professional rugby league. J Sports Sci 2011;29:1453-61.

35. Usman J, Mclntosh AS, Fréchède B. An investigation of shoulder forces in active shoulder tackles in rugby union football. J Sci Med Sport 2011;14:547-52.

36. Waldron $\mathrm{M}$, Worsfold $\mathrm{P}$, Twist $\mathrm{C}$, et al. The reliability of tests for sport-specific skill amongst elite youth rugby league players. Eur $J$ Sport Sci 2014;14(Suppl 1):S471-S477.

37. Lacome M, Piscione J, Hager JP, et al. Analysis of running and technical performance in substitute players in international male rugby union competition. Int J Sports Physiol Perform 2016;11:783-92.

38. Wu WL, Chang JJ, Wu JH, et al. An investigation of rugby scrimmaging posture and individual maximum pushing force. $J$ Strength Cond Res 2007;21:251-8.

39. Vaz L, Leite N, João PV, et al. Differences between experienced and novice Rugby Union players during small-sided games. Percept Mot Skills 2012;115:594-604.

40. Higgins T, Cameron M, Climstein M. Evaluation of passive recovery, cold water immersion, and contrast baths for recovery, as measured by game performances markers, between two simulated games of rugby union. J Strength Cond Res 2012:1.

41. Gabbett TJ, Jenkins DG, Abernethy B. Physiological and skill demands of 'on-side' and 'off-side' games. J Strength Cond Res 2010;24:2979-83.

42. Sirotic AC, Knowles $\mathrm{H}$, Catterick $\mathrm{C}$, et al. Positional match demands of professional rugby league competition. J Strength Cond Res 2011;25:3076-87.

43. Lacome M, Piscione J, Hager JP, et al. Fluctuations in running and skill-related performance in elite rugby union match-play. Eur $J$ Sport Sci 2017;17:132-43.

44. Linthorne NP, Stokes TG. Optimum projection angle for attaining maximum distance in a rugby place kick. J Sports Sci Med 2014;13:211-6.

45. Cockcroft J, Van Den Heever D. A descriptive study of step alignment and foot positioning relative to the tee by professional rugby union goal-kickers. J Sports Sci 2016;34:321-9.

46. Gabbett TJ, Abernethy B. Dual-task assessment of a sporting skill: influence of task complexity and relationship with competitive performances. J Sports Sci 2012;30:1735-45.

47. Gabbett T, Wake M, Abernethy B. Use of dual-task methodology for skill assessment and development: examples from rugby league. J Sports Sci 2011;29:7-18.

48. Gabbett T, Kelly J, Pezet T. A comparison of fitness and skill among playing positions in sub-elite rugby league players. J Sci Med Sport 2008;11:585-92. 